\title{
Perceived Benefits of Spa Experiences: Tourist Insights from the Blogosphere
}

\author{
Jenny H. Panchal * \\ James Cook University, Singapore
}

\begin{abstract}
The Asian spa has seen considerable growth in recent years. Nonetheless, the dearth in the literature about the spa industry in Asia is evident. Tourist spa experiences are an intriguing aspect in this industry. In this study, blog analysis, which involved a progressive four-stage process, was employed to explore travel bloggers' spa experiences in India, Thailand and the Philippines. More specifically, this paper presents overview of travel blogs that contain accounts of tourist spa experiences as well as bloggers' perceived benefits from their spa experiences. The findings suggest that spa experiences are by and large positive experiences that benefit multiple dimensions of tourist well-being.
\end{abstract}

Keywords: Asian spa experience; tourist experience; travel blogs; well-being; wellness.

* Lecturer, School of Business, James Cook University (JCU) Singapore, Singapore.

E-mail: jenny.panchal@jcu.edu.au 


\section{Introduction}

Spa tourism is one of the types of health and wellness tourism that has received much attention in recent years. Asian spa tourism, in particular, is recognized as a booming industry (Laing \& Weiler, 2008; Panchal \& Pearce, 2011). While enthusiastic promotional statements about rapidly growing tourism sectors often exaggerate the importance of a special area, the numbers of properties and participants support a claim that spa tourism is of considerable importance. Research focusing on this forum of tourism in the Asia Pacific region, nonetheless, is very limited. There are descriptive accounts of the spa industry, much promotional material and many claims, but little published academic research. This identified gap in knowledge has been taken as an opportunity to study tourist behavior in the light of spa-going activities in Asia.

Tourist spa experiences in Asia are argued to provide a rich source of information in understanding tourist behavior in Asia in the context of health and wellness tourism. Nevertheless, Caru and Cova (2008) suggest that experiences cannot be directly accessed by research. Travel blogs, however, are a "manifestation of travel experience" (Pan, MacLaurin, \& Crotts, 2007) and can be thought of as more representative of the 'real' thoughts and feelings of consumers (Carson, 2008). The results of this study, which attempted to access the thoughts and feelings of travel bloggers in the context of spa experiences, can be linked to the existing corpus of knowledge that underpins the relationship between tourist experiences and aspects of well-being in the context of Asian spa tourism.

The use of travel blogs in accessing tourist experiences is one of the novel contributions of this paper. While netnography or online ethnography has been employed by various researchers in the study of tourism, particularly in understanding tourist behavior, it is evident that accounts of tourist spa experiences have not been previously explored using this method. It is important to note that this paper is part of a larger study that highlights the existing but under-researched relationship between tourism and positive psychology in the context of Asian spa tourism. The broad research investigated the relationship by understanding tourist motivations, the experience of flow and the perceived benefits of spa experiences. Hence, at core, this paper explores spa experiences in Asia. More specifically, this paper aims to identify the corpus of travel blogs about spa experiences in South East 
Asia, particularly in India, Thailand and the Philippines. This paper subsequently highlights the travel bloggers' perceived benefits of their spa experiences in these three countries. The benefits identified in this paper refer to the positive outcomes that the travel bloggers had during their spa experience.

The focus on Asian spa tourism is one of the novel points of this study. The terms “Asia” or "Asian spa”, however, is too broad to identify the geographical milieu of this study. To clarify this, it is important to demarcate the specific focus of this research in geographical terms. According to the United Nation's geographical region classification (United Nations Department of Economic \& Social Affairs, 2011), Thailand and the Philippines are part of Southeast Asia while India is a big part of South Asia. Although South and Southeast Asia are two different sub-regions, they are collectively labelled as "South East Asia” in this paper to avoid redundancy and verbosity in the text. The term South East Asia will therefore be used throughout this paper for consistency.

This paper highlights three important contributions in knowledge, in commercial considerations and practical applications. The conceptual contribution of this study lies in the use of a four-stage data collection method to explore tourist spa experiences in Asia. The findings in this study suggest that spa experiences benefit tourists not only in the physical or psychological domain, but also in the social and environmental aspects of their wellbeing. By and large, these findings underpin the importance of spa activities as sources of positive experiences for tourists. The commercial and practical implications that are offered in this paper relate to marketing opportunities and enhancing spa business potentials.

\section{Health \& Wellness as Tourism Products \& Experience}

\section{Health \& Wellness Tourism}

As tourism products, health and wellness are popular contemporary tourism experiences. At core, wellness is a relative and subjective state of being that is inherently multidimensional but where the integrative sum of the component parts must also be appreciated. In the course of the history of wellness as a concept, academics and non-academics have identified many dimensions of wellness. The most frequent facets of wellness include physical, spiritual, mental and social dimensions (Panchal \& Pearce, 2011; Pearce \& Panchal, 
2010).

The health-wellness-tourism interface represents a long standing relationship that dates back to ancient times. Owing to the Greek and Roman discovery of the healing qualities of water, people started travelling to mineral springs and seaside resorts to recuperate, relax and/or escape from the imperial metropolis. In modern tourism, travelling for health and wellness persists as an activity (Laing \& Weiler, 2008; Smith \& Kelly, 2006a; 2006b; Smith \& Puczko, 2009). Tourist experiences are tourism products; this is to say that the experience of travelling for wellness reasons as well as the experience of participating in tourist activities that promote health and wellness can be regarded as tourism products.

The literature on health and wellness tourism provides two established categories: medical and spa tourism. The health and relaxation component that spas offer in addition to the traditional holiday makes health and wellness tourism an area of rising popularity (Didascalou, Nastos, \& Matzarakis, 2007). Although this is a more recent observation, historical accounts on the origins of spa assert otherwise. While medical tourism is a more contemporary form of tourism, the earliest forms were directly aimed at increased health and wellbeing; one of which is spa tourism (Connell, 2006). Although it was not termed as such, "taking the waters" was common by the $17^{\text {th }}-19^{\text {th }}$ centuries in many parts of Europe (Douglas, 2001; Henry, 2005; Iovine, 2005; Kaspar, 1990; Laing \& Weiler, 2008). Spa tourism is a subtle subset of health and wellness tourism in terms of treatments and therapies.

\section{The Asian Spa}

Smith and Kelly (2006a) describe spa tourism as "tourism which focuses on the relaxation or healing of the body using water-based treatments, such as pools, steam rooms and saunas. Emphasis tends to be focused on relaxation and health and beauty treatments rather than the spiritual aspect of certain exercises such as yoga. Surroundings are usually sumptuous with pricing schemes to match” . Similarly, Hall (2005, p. 275) defines spa tourism as “a component of health tourism that relates to the provision of specific health facilities and destinations which traditionally include the provision of mineral waters by which may also be used to refer to tourist resorts that integrate health facilities with accommodation." Both definitions suggest that water is a significant element in spa tourism, especially in Europe - the home of the spa. 
While these definitions may be used mainly in North American or European context, they cannot be used as universal definitions of spa tourism because they are not necessarily applicable to Asian spas. The inclusion of the term water in these definitions makes it appear that water is the main element used in spa treatments and therapies. Water and its natural sources such as mineral hot springs are also recognised to have therapeutic effects in Asia (e.g. Japan and Korea). Nonetheless, many other Asian spa practices are not just reliant on water. The use of nature-derived mineral and essential oils is a widespread Eastern practice (e.g. massages).

Indeed, nature is an integral part of the Asian spa. The Asian spa phenomenon is more than just a massage or a scrub; in particular, the daily rituals and ceremonies are all part of Asians' way of life and are designed to restore the body and soul (Chapman, 2006). Chapman (2006) suggests that the prime focus of most Asian spas is to return the body to a balanced state through ancient botanical recipes and time-honoured rituals. Apart from minerals and oils, herbs, spices, certain root crops (e.g. ginger) and parts of plants and trees are believed to have healing and/or soothing benefits and hence are used in traditional spa treatments.

Revered as the "home to the world's richest and most diverse spa culture" by the Spa Wellness Council (2008), the Asia Pacific region is the world's third largest spa market in terms of revenues (more than $24 \%$ of the global spa revenues) and the second largest market in terms of number of spas employing more than 360,000 people in total (Table 1). The 2007 Global Spa Economy contains the most complete and most recent data on Asia-Pacific's spa industry profile. Even without the Pacific region (i.e. Australia, New Zealand and the small island states), the Asian spa industry is considerable with an estimated combined revenue of about US\$8,642 million in Japan, China and South Korea alone. Additionally, India and Thailand have a combined contribution estimated to be US\$778 million (SRI, 2008).

Table 1. Global Spa Facilities by Region, 2007.

\begin{tabular}{lccc}
\hline \hline & $\begin{array}{c}\text { Estimated Total } \\
\text { Number of Spas }\end{array}$ & $\begin{array}{c}\text { Estimated Total Spa } \\
\text { Revenues } \\
\text { (US\$ billions) }\end{array}$ & $\begin{array}{c}\text { Estimated Total Spa } \\
\text { Employment }\end{array}$ \\
\hline Europe & 22,607 & $\$ 18.4$ & 441,727 \\
\hline Asia-Pacific & $\mathbf{2 1 , 5 6 6}$ & $\mathbf{\$ 1 1 . 4}$ & $\mathbf{3 6 3 , 6 4 8}$ \\
\hline North America & 20,662 & $\$ 13.5$ & 307,229 \\
\hline Middle East-North Africa & 1,014 & $\$ 0.7$ & 20,938 \\
\hline \hline
\end{tabular}




\begin{tabular}{lccc}
\hline \hline Latin America-Caribbean & 5,435 & $\$ 2.5$ & 82,694 \\
\hline Africa & 349 & $\$ 0.3$ & 7,273 \\
\hline Total & $\mathbf{7 1 , 6 7 2}$ & $\mathbf{\$ 4 6 . 8}$ & $\mathbf{1 , 2 2 3 , 5 1 0}$ \\
\hline \hline
\end{tabular}

(Source: 2007 Global Spa Economy by the SRI, 2008)

Much of Asia's age-old wellness traditions, which have been a way of life for many generations, are now being shared with the rest of the world through their practice not only in Asian spas but also in Western societies' spas. The Thai massage and the Japanese shiatsu massage, for instance, are traditional healing methods that have gained popularity across the globe. Arguably, almost every spa in the world offers shiatsu massage. Similarly, relaxation practices of Eastern origins such as yoga and meditation have also become well-liked worldwide. Each country in Asia has its own spa heritage to offer (Chapman, 2006; Spa Wellness Council, 2008). At a fundamental level, it can be said nonWestern countries share their wealth of traditions and ancient practices with each other, if not the world. Cupping (suction through the skin), for example, is not just a Chinese tradition but it is also practiced in Arab countries (Mind Body \& Soul, 2009). Apart from treatments, the use of indigenous ingredients and materials are now being used in modern-day spas.

In the Indian sub-continent, Ayurveda is the oldest and widely practised health and wellness system, and India is the top destination for this type of healing. Ayurvedic tourism is also marketed as part of the global growth in health tourism fuelled by widespread trends including aging populations, high rates of stress and increased interest in health most specifically amongst affluent individuals (Messerli \& Oyama, 2004). The literature on Ayurveda tourism describes the practice as a gentle system of holistic healing that is rooted in old traditions while exhibiting a modern and professionalised stance supported by scientific research (Spitzer, 2009). Sahoo (2006; cited in Spitzer, 2009) suggests that this type of tourism in India attracts Westerners exploring the ancient art and science of the exotic other as well as citizens of South East Asia, West Asia, and members of the global South Asian diasporas of 20 million persons who reside in 70 countries. Apart from international tourists, domestic tourists visit popular Ayurvedic destinations such as the state of Kerala in South India. The treatments in Ayurveda are akin to those of spas (e.g. massage, facials) which promote relaxation and harmony of mind, body and spirit (Kerala Ayurveda Tourism, 2009). As noted by ISPA, the Ayurvedic resorts can be classified as destination spas, while day-use Ayurveda centres 
are categorised as “other spas”.

In other parts of Asia, traditional/indigenous healing methods are also used in spas. In the Philippines, for instance, 'hilot' is an ancient massage technique that is now on spa menus in the country. Alave (2012) notes that its benefits are comparable to Chinese acupuncture, aromatherapy and even Western medicine. Apart from 'hilot', some spas in the Philippines also include 'dagdagay' (an indigenous tribal foot massage using bamboo sticks) and the use of the 7-herb concoction (known as 'pito-pito') in bath treatments (Sanctuario Spa, 2009). Also in many parts of Asia, traditional Chinese treatments are common; acupuncture, body smoking and cupping (suction through the skin) are being offered in spas (The Spa Village, 2008), and are also used in Western societies (Mind Body \& Soul, 2009). The products used in Asian spa treatments and therapies may also be indigenous. In spas in the Cordillera region in the Philippines, for instance, local produce such as rice, coffee and strawberries are used as scrubs (North Haven Spa, 2007). In traditional Malay treatments, turmeric, piper betel and pandanus leaves are widely used (The Spa Village, 2008)

\section{Netnography: of Travel Blogs \& Tourist Experiences}

Studying experiences through blogs is referred to as netnography; it is also known as "online ethnography" or "ethnography on the Internet” (Kozinets, 2002). The term "netnography” is defined by Kozinets in two ways: as a research methodology and as a product. As a methodology, it is "a new qualitative research methodology that adapts ethnographic research techniques to study the cultures and communities that are emerging through computermediated communications" (2002, p. 62). As a product, netnography is a "written account of online cyber culture, informed by the methods of cultural anthropology” (1997, p. 470). As a qualitative, or more specifically an interpretive method, netnography originates from ethnography and anthropological research and is now commonly used in consumer and marketing research (cf. Kozinets, 1997, 1998, 1999; 2002) as well as in tourism research (cf. Crotts, Mason, \& Davis, 2009; Pan et al., 2007). Since it is based on the observation of textual discourse alone, this method differs from the balancing of discourse and observed behaviour that occurs during in-person ethnography (Arnould \& Wallendorf, 1994; cited in Kozinets, 2002). 
Because the adaptation of ethnographic techniques to the online environment is not straightforward (Kozinets, 2010; Rice \& Rogers, 1984), it is imperative to identify the differences between face-to-face ethnography and computer-mediated communications. Kozinets (2010, p. 68) has therefore emphasised four critical points of difference to consider when employing netnography as a research method: 1) the nature of the researcher-respondent interaction due to the nature and rules of the technological medium; 2) the anonymity of participants; 3) the accessibility of a plethora of online forums open to participation by anyone; and, 4) the automatic archiving of conversations and data facilitated by the online medium.

Research cannot directly access an individual's experiences (Caru \& Cova, 2008). Travel blogs, however, are a "manifestation of travel experience" (Pan et al., 2007, p. 35) which can serve as a representation of people's real thoughts and feelings (Carson, 2008). As they are akin to travel diaries, travel blogs are credible and realistic accounts of travel experiences. As Nardi, Schiano, Gumbrecht and Swartz (2004) suggest, there are five intrinsic motivations for blogging which are not mutually exclusive and may come into play simultaneously: to document one's life, to provide opinions and commentary, to express deeply felt emotions, to articulate ideas through writing and to form and maintain community forums. The desire to share experiences with family, friends and other potential tourists also exist (Sharda \& Ponnada, 2008). Sharda and Ponnada (2008) add that self-expression, interaction and information enhancement are also factors motivating bloggers. Travel blogs are indicative of human thoughts, opinions and feelings neatly recorded in text and sometimes in photographs.

There are many scholars and researchers who have employed netnography in their studies. Some have used it to understand tourist experiences and behaviour, but no evidence of this method in exploring tourists' spa experiences was found. Pan and colleagues (2007), for example, used semantic network and content analyses and found that bloggers usually wrote about their travel experiences and emphasised the advantages of using travel blogs when describing guests' likes and dislikes in terms of their purchase experiences with destination organizations. They strongly advocate that travel blogs are economical sources of rich, authentic and unsolicited customer feedback. Pearce and Foster (2007) have used backpackers' travelogues from which they drew quotes revealing that skills were used, gained or developed as a result of 
travel experiences. Douglas and Mills (2006) studied 350 blogs from the travel blog site TravelPod to identify the brand images communicated by travel bloggers who visited North Africa and the Middle East. They suggested that accessing travellers' attitudes may also be a useful tool in shaping marketing ideas by identifying the positive characteristics that bloggers report about a destination.

\section{Asian Spa Experiences in Travel Blogs}

This paper aims to ascertain the body of accounts of spa experiences in India, Thailand and the Philippines in travel blogs and to identify the perceived benefits that travel bloggers had from their spa experiences in these countries. The technique to select the blogs for this study had to marry insightfulness and representativeness, as suggested by Decrop (2004). The procedure adopted in this project was a four-stage process, following certain criteria in each stage for consistency. The sifting of information through these four stages was important to meet the objectives of the study. The first aim was to identify the volume of information about spa experiences in South East Asia, particularly in India, Thailand and the Philippines, in travel blogs found in the three leading travel blog sites. The first and second stages of this method were helpful in addressing this aim. The first stage involved recognizing the diversity and volume of available travel blogs, including identifying three travel blog sites (i.e. TravelPod, Travel Blog and Lonely Planet Blogs) as productive sources of sparelated tourist blogs. The second stage involved filtering the blogs through a coding process, which aided in classifying blogs according to tourists' detailed accounts and their perceived benefits from their spa experience. The third and fourth stages focused on reports of people experiencing or having experienced spa treatments rather than anticipating such treatments, which provided a better understanding of travel bloggers' thoughts and feelings about their experiences. These phases of the data collection and analysis helped address the second aim, to identify the travel bloggers' perceived benefits of their spa experiences in these three countries.

The mechanism used to search for blogs was also multi-staged and involved mixing and matching spa-related key words (e.g. spa, spa experience, spa holiday, wellness holiday, massage) from the broadest to the specific geographical context of the research (i.e. Asia, South Asia, Southeast Asia, 
India, Thailand, Philippines). A total of 56 combinations were recorded from each blog site. Instead of taking a certain percentage of these blogs for extended analysis, the blog selection was taken through a further filtering process in the second stage. Because of the volume of blogs that resulted from the initial searches of the travel blog sits, the blogs that were considered for further analysis had to have been published between 2005 and 2010 only. The blogs published before and beyond this period were disregarded in the later stages of this study.

\section{Results \& Discussion}

\section{Stages 1 \& 2 - Blog Search and Coding}

Due to the copious number of blogs that resulted from the initial search, only the blogs with spa-related key words matched with "India", "Thailand" and "Philippines" were selected. This process avoided redundancy and the possibility of analyzing one blog multiple times, and ensured focus and consistency. Overall, the number of blogs that relate to India, Thailand and the Philippines were thought to be more manageable and better suited to this study than a selection from a continent or sub-region. Also, a more diverse collection of blogs can be expected when the selection is not limited to blogs from 3-4 cities/towns in each country. More than 47 per cent of the blogs were taken from Travel Blog ( $n=458)$, while about 40 per cent were from Travel Pod ( $n=$ 394). The blogs from Lonely Planet that were used for analysis were marginal in number $(\mathrm{n}=120,12.3 \%)$. Most of the blogs were about spa experiences in Thailand $(\mathrm{n}=584,60.1 \%)$.The blogs about India accounted for almost 30 per cent of the sample, while those about the Philippines represented only 10 per cent of the total sample (Table 2).

Table 2. Number of blogs accessed and coded for the study

\begin{tabular}{cccccc}
\hline TravelPod & TravelBlog & $\begin{array}{c}\text { Lonely Planet } \\
\text { Blogs }\end{array}$ & Total & $\begin{array}{c}\text { Number of coded } \\
\text { blogs (1\% of the } \\
\text { total) }\end{array}$ \\
\hline \hline India & 5,883 & 32,631 & 904 & 39,418 & $\mathbf{3 9 4}$ \\
\hline Thailand & 6,155 & 37,554 & 2,090 & 45,799 & $\mathbf{4 5 8}$ \\
\hline Philippines & 1,189 & 10,598 & 242 & 12,029 & $\mathbf{1 2 0}$ \\
\hline Total & $\mathbf{1 3 , 2 2 7}$ & $\mathbf{8 0 , 7 8 3}$ & $\mathbf{3 , 2 3 6}$ & $\mathbf{9 7 , 2 4 6}$ & $\mathbf{9 7 2}$ \\
\hline \hline
\end{tabular}


The second stage of this study was aimed at filtering the blogs that were accessed in Stage 1. This was effectively an initial stage of blog coding which was essential in identifying relevant blogs for further analysis. A relevance guide that involved a coding system was employed, as shown in Table 3.

Table 3. The coded sample: Travel blog sites and location of spa experience

\begin{tabular}{|c|c|c|c|c|c|c|c|c|c|c|c|c|}
\hline & & & \multicolumn{10}{|c|}{ Blog Code } \\
\hline & & & \multicolumn{2}{|c|}{1} & \multicolumn{2}{|c|}{2} & \multicolumn{2}{|c|}{3} & \multicolumn{2}{|c|}{4} & \multicolumn{2}{|c|}{5} \\
\hline & & & $\mathrm{N}$ & $\%$ & $\mathrm{~N}$ & $\%$ & $\mathrm{~N}$ & $\%$ & $\mathrm{~N}$ & $\%$ & $\mathrm{~N}$ & $\%$ \\
\hline \multirow{12}{*}{$\begin{array}{l}\text { Blog } \\
\text { site }\end{array}$} & \multirow{3}{*}{$\begin{array}{c}\text { Travel } \\
\text { Pod }\end{array}$} & India & 66 & 31 & 28 & 27 & 31 & 32 & 18 & 34 & 10 & 22 \\
\hline & & Thailand & 129 & 61 & 67 & 64 & 57 & 59 & 32 & 60 & 32 & 71 \\
\hline & & Philippines & 18 & 8 & 9 & 9 & 9 & 9 & 3 & 6 & 3 & 7 \\
\hline & \multicolumn{2}{|c|}{ Total } & 213 & 100 & 104 & 100 & 97 & 100 & 53 & 100 & 45 & 100 \\
\hline & \multirow{3}{*}{$\begin{array}{l}\text { Travel } \\
\text { Blog }\end{array}$} & India & 80 & 31 & 41 & 29 & 30 & 33 & 18 & 33 & 22 & 28 \\
\hline & & Thailand & 149 & 59 & 84 & 59 & 51 & 57 & 32 & 59 & 49 & 63 \\
\hline & & Philippines & 25 & 10 & 18 & 13 & 9 & 10 & 4 & 7 & 7 & 9 \\
\hline & \multicolumn{2}{|c|}{ Total } & 254 & 100 & 143 & 100 & 90 & 100 & 54 & 100 & 78 & 100 \\
\hline & \multirow{4}{*}{$\begin{array}{c}\text { Lonely } \\
\text { Planet } \\
\text { Blogs }\end{array}$} & India & 22 & 33 & 7 & 21 & 9 & 32 & 9 & 50 & 2 & 18 \\
\hline & & Thailand & 42 & 64 & 22 & 65 & 14 & 50 & 7 & 39 & 6 & 55 \\
\hline & & Philippines & 2 & 3 & 5 & 15 & 5 & 18 & 2 & 11 & 3 & 27 \\
\hline & & otal & 66 & 100 & 34 & 100 & 28 & 100 & 18 & 100 & 11 & 100 \\
\hline
\end{tabular}

1 - The blogger mentioned "spa” but did not have any spa experience during that trip;

$\mathbf{2}$ - The blogger merely mentioned about the spa treatment that he/she had, but did not elaborate on the experience;

3 - The blogger gave relatively more detail about the spa treatment that he/she had, but did not elaborate on the experience;

4 - The blogger wrote about his/her thoughts and feelings during the spa experience; and,

5 - The blogger wrote about his/her thoughts and feelings after the spa experience.

There were, however, more complex blogs were uncovered. The complexity of these blogs lay in the assortment of spa treatments received by the blogger, as well as in the heterogeneity of the blogger's thoughts and feelings about the spa experience(s). In a single blog that contained accounts of multiple spa experiences in the same trip, for example, each spa visit was treated as a single experience. It should be noted, nonetheless, that a single spa visit may have involved multiple spa treatments (e.g. massage combined with body scrub and a facial). Such combinations of treatments are often bought as a 'treatment package', hence treated as a single unit of experience. This special criterion employed at this stage was based on the accepted notion that tourist services and experiences are heterogeneous in nature (Bowen \& Clarke, 2009; Cohen, 
1979, 1996; Lopez-Bonilla \& Lopez-Bonilla, 2010). Bowen and Clarke (2009) argued that "no two customers... no two employees... no two service acts are alike", thereby suggesting that no two experiences are exactly alike. The heterogeneous pattern of experiences was evident in a few of the blogs where the authors wrote about the differences between their spa treatments (i.e. both were massages) in two different places. In one blog, the blogger described one experience as "relaxing", and the subsequent experience as "painful". In another blog, the foot spa in the first visit was "ticklish", while the second was "soothing". This non-uniformity in spa experiences was a compelling reason to isolate one spa visit from another in a single blog.

Although most of the blogs had multiple codes by this stage, only the blogs coded $\mathbf{4}$ and $\mathbf{5}$ were considered for further analysis. It should also be noted that only blogs written in English were selected, and no further sub-selection criteria such as gender or nationality were employed. It can be observed that wherever possible, it is valuable to record these variables in interpreting communication efforts as they have been shown to have some impacts on traveler self-disclosure (Pearce, 1991). The sample in this study was presumed to cover a broad range of cases and influencing factors for initial consideration and screening (Veal, 2004). It was initially thought that the spa-related trips would contain very detailed accounts of the spa experience. It was, however, not the case. Although many of the blogs under the related trips category contained relevant spa experience stories, many blogs outside this focused spa travel were also found to be useful.

\section{Stages 3 \& 4 - Bloggers Thoughts and Feelings During and After the Spa Experience}

The third and fourth stages of the blog selection process involved only the blogs that were coded "4" and " 5 " in the sample. In each of these final stages, the only criterion for the blogs to be included in further analysis was that the bloggers should have written about his/her thoughts and feelings during and after the spa experience. There were 125 blogs that were included in the analysis; more than 43 per cent of them were from Travel Blog $(n=54)$, while about 42 per cent were from Travel Pod $(n=53)$. As expected, the majority of the blogs that were coded " 4 ", and based on experience in Thailand ( $\mathrm{n}=71$, $56.8 \%$ ). Similarly, the number of blogs included in Stage 4 (coded "5") was 134 (13.8\% of the total sample). Thailand-based spa experience accounts were 
dominant in this sample ( $\mathrm{n}=87,64.9 \%$ ).

Overall, the approach employed in filtering the data was the conventional, long-hand method. The blogs were printed on A4 paper (2-sided), and were subsequently coded. In the third and fourth stages of filtering the blogs, about 30 stories were randomly chosen to identify recurring themes. In the Stage 3 analysis, it was evident in the reports of "feeling good" and similar moods of spa-goers, that the focus during the treatment was the "self" and how they felt. The positive experiences were divided into three dimensions: physical, which refers to any feeling that they felt pertaining to the body; psychological, which refers to their feelings, moods and other sensations that the physical body does not directly or necessarily feel; and, social/environmental, which refers to how they respond not only to people around them during the treatment, but also to other certain products that were being used as part of the therapy.

\section{The Travel Bloggers' Profile}

The bloggers whose accounts of spa experiences were coded in the second stage of this study were profiled according to the most explicit information that could be gathered from their profile and in some cases, their stories. Although the gender of about 34 per cent of the bloggers was ambiguous or unidentified $(n=331)$, almost 36 per cent were females $(n=347)$, and about 16 per cent males $(n=154)$. Some of the travel blogs were also observed to be co-owned or co-authored. These bloggers were identified as a couple/group cohort $(n=140$, $14.4 \%)$. About $2.5 \%(n=24)$ of bloggers had more than one blog in the current study.

From the accounts of these travel bloggers, an attempt was made to identify who they were travelling with (travel party variable). Because of the freestyle structure and the varying length of the blogs, it took some time to gather the information and it was challenging to follow some of the stories. Almost 43 per cent of the bloggers were either travelling alone $(n=206,21.2 \%)$ or with their partner/spouse $(n=211,21.7 \%)$. About 23 per cent were travelling with their family, some with children ( $\mathrm{n}=109,11.2 \%)$ and some were without children (n $=111,11.4 \%)$. Interestingly, nearly eight per cent of them were travelling with friends, and almost five per cent were with people whom they had met while on holiday (e.g. fellow backpacker). Almost 22 per cent were unidentified/ambiguous $(\mathrm{n}=212)$. 
Table 4. Cross-tabulation: Blog site vs. (destination) location of spa experience

\begin{tabular}{|c|c|c|c|c|c|}
\hline & & \multicolumn{3}{|c|}{ Blog site } & \multirow{2}{*}{ Total } \\
\hline & & Travel Pod & Travel Blog & Lonely Planet & \\
\hline \multirow{5}{*}{ India } & Count & 118 & 137 & 36 & 291 \\
\hline & Expected Count & 118.0 & 137.1 & 35.9 & 291.0 \\
\hline & \% within Location & $40.5 \%$ & $47.1 \%$ & $12.4 \%$ & $100.0 \%$ \\
\hline & \% within Blog site & $29.9 \%$ & $29.9 \%$ & $30.0 \%$ & $29.9 \%$ \\
\hline & $\%$ of Total & $12.1 \%$ & $14.1 \%$ & $3.7 \%$ & $29.9 \%$ \\
\hline \multirow{5}{*}{ Thailand } & Count & 237 & 275 & 72 & 584 \\
\hline & Expected Count & 236.7 & 275.2 & 72.1 & 584.0 \\
\hline & \% within Location & $40.6 \%$ & $47.1 \%$ & $12.3 \%$ & $100.0 \%$ \\
\hline & \% within Blog site & $60.2 \%$ & $60.0 \%$ & $60.0 \%$ & $60.1 \%$ \\
\hline & $\%$ of Total & $24.4 \%$ & $28.3 \%$ & $7.4 \%$ & $60.1 \%$ \\
\hline \multirow{5}{*}{ Philippines } & Count & 39 & 46 & 12 & 97 \\
\hline & Expected Count & 39.3 & 45.7 & 12.0 & 97.0 \\
\hline & \% within Location & $40.2 \%$ & $47.4 \%$ & $12.4 \%$ & $100.0 \%$ \\
\hline & \% within Blog site & $9.9 \%$ & $10.0 \%$ & $10.0 \%$ & $10.0 \%$ \\
\hline & $\%$ of Total & $4.0 \%$ & $4.7 \%$ & $1.2 \%$ & $10.0 \%$ \\
\hline \multirow{5}{*}{ Total } & Count & 394 & 458 & 120 & 972 \\
\hline & Expected Count & 394.0 & 458.0 & 120.0 & 972.0 \\
\hline & \% within Location & $40.5 \%$ & $47.1 \%$ & $12.3 \%$ & $100.0 \%$ \\
\hline & \% within Blog site & $100.0 \%$ & $100.0 \%$ & $100.0 \%$ & $100.0 \%$ \\
\hline & \% of Total & $40.5 \%$ & $47.1 \%$ & $12.3 \%$ & $100.0 \%$ \\
\hline
\end{tabular}

\section{Positive Spa Experiences During the Spa Treatment}

In the analysis of blogs that were coded " 4 ” $(n=125)$, it was observed that the observations of the spa-goer/blogger were focused on the self. Most of the thoughts and feelings reported in relation to their on-going spa experience were emic and personal. As mentioned in the previous section, reports of the bloggers' own positive feeling and moods became apparent even at the outset of the analysis. A total of 12 key themes were identified from the blogs. The themes were later grouped and represented three dimension of a person's wellbeing: physical ("of the body”), psychological (of feelings, moods, thoughts and sensations that were not "of the body"), and social/environmental (of awareness of one's relationships not only with people but also with nature). The bloggers' comments were coded into these categories but since the material is spontaneously generated, the words used to fit into these counts varied in frequency. 
Table 5. Stage 3 - Positive spa experiences during the spa treatment

\begin{tabular}{lcc}
\hline \hline Bloggers' Thoughts/Feelings & $\begin{array}{c}\text { Raw Count } \\
\text { (Total = 125) }\end{array}$ & $\begin{array}{c}\text { \% of all relevant coded } \\
\text { blogs }\end{array}$ \\
\hline \hline A. Physical & & 67.2 \\
\hline Relaxing & 84 & 17.6 \\
\hline Muscles loosening up & 22 & 45.6 \\
\hline Invigorating/energizing (feeling of strength/vigour) & 57 & 24.8 \\
\hline Ticklish & 31 & 32.8 \\
\hline Warmth & 41 & 33.6 \\
\hline B. Psychological & & 10.4 \\
\hline Relaxing (for the mind) & 42 & 22.4 \\
\hline Feeling of lightness/weightlessness & 13 & 14.4 \\
\hline Peaceful & 28 & 17.6 \\
\hline Calm & 18 & 24.8 \\
\hline C. Social/Environmental & & 20.8 \\
\hline Positive connections with companion(s) & 22 & \\
\hline Appreciation of nature-derived products & 31 & \\
\hline Appreciation of nature & 26 & \\
\hline \hline
\end{tabular}

\section{The Physical Dimension}

The most prominent thought among the spa-goers during treatments was the feeling of being relaxed. Two types of relaxation were observed in the blogs. One was physical relaxation $(n=84,67.2 \%)$, and the other mental relaxation ( $n$ $=55,44 \%)$. Although the idea of mental relaxation fits well with the psychological dimension, its inclusion in this discussion is important because of its linkage to a few related observations. Relaxation as a thought/feeling during a spa treatment is uncommon. There are two factors that can be related to this finding. One is the treatment being received, and the other relates to the ambience of the place.

It is somewhat predictable that massage is the most popular spa treatment as underpinned in both commercial and academic studies, including this research. While many respondents have identified massage as their preferred treatment, it was difficult to ascertain the type of treatment that many bloggers had during their spa visit. Regardless of the treatment, however, many of the travel blog authors reported a soothing and/or calming effect that the treatment had on their bodies and minds. Indeed, touch has been part of healing in several cultures and civilizations over many centuries. In the context of spa services, touch is inevitable and is thought of as a very important tool in the spa experience. Touch therapy, especially in the field of care-giving, is seen to be highly 
beneficial. In the field of medicine, the benefits of touch therapy are welldocumented. Massage, the most popular treatment is spas, is defined by the US National Institutes of Health (NIH) as "the manipulation of muscles and their tendons, ligaments and other connective tissue by applying pressure to the body" (2010). Massage is proven to help the body release certain chemicals that aids in relaxation, improving blood circulation and eliminating toxic substances from the muscles(NIH, 2010).

The other factor that was observed to have contributed to these claims was the spa ambience where pleasant aromas, soothing interiors and relaxing music were important elements. Nathan, a blogger from the USA who was backpacking in Thailand recounted, "...the smell of that oil... it must have been lemongrass or lavender or something made me want to go to sleep... I can't remember the last time I felt that relaxed..." (Blog 334). Similarly, Marianne felt that the sound of gushing water and birds chirping in the background made her feel that she was "in the middle of a garden... My eyes were closed but they felt real!! That spa tricked me into thinking that I was in some Garden of Eden. The sound of water and birds were from a CD!!"(Blog 576). While many of the bloggers found the experience relaxing and soothing, more than 45 per cent (n =57) claimed to have felt invigorated during the treatment.

Claims of loosening muscles, ticklish feelings and warmth were also prominent in the results. The idea of loosening muscles during treatment $(\mathrm{n}=$ $22,17.6 \%)$ is an indicator that a massage was received at the spa. The loosening of stiff and sore muscles is just an immediate precursor to a more lasting end that is, relaxation. Interestingly, about 25 per cent felt ticklish during the treatment $(\mathrm{n}=21,24.8 \%)$. For some people, feeling ticklish is a negative experience. Nonetheless, feeling ticklish was treated as a positive theme in this study because the bloggers who felt the sensation recognized the spa experience as positive overall. Reports on warmth were somewhat ambiguous in most stories. The more straightforward accounts of warmth, however, were more inclined towards the physical dimension. In one story for example, Alvin wrote, "The air-conditioner was blowing directly at me. I removed my clothes and I was cold. The towel provided warmth but when the massage started I forgot how cold it was in the room... I fell asleep during the massage...” (Blog 799).

\section{The psychological dimension during treatment}

As discussed earlier, mental relaxation was highlighted as an instantaneous 
benefit of spa treatments. The benefits of touch in one's mental state are indeed emphasized in the study of medicine. Gagne and Toye (1994), for example, suggest that touch therapy aids in the significant reduction of reported anxiety. Many people who get massages feel better taken care of because of the touch and contact with the therapist (National Institutes of Health, 2010). Another benefit related to mental relaxation is the reported recovery from fatigue $(\mathrm{n}=$ 20, 16\%). At first, it was thought of as a physical rather than a psychological element because of its association with physical relaxation. It was, however, observed that the description of the experience related more to the bloggers' state of mind than of the body. Expressions such as "I felt the stress evaporating” (Alvin, Blog 799) was a psychological element more than a physical element.

Feelings of peacefulness $(n=28,22.4 \%)$ and of calmness $(n=18,14.4 \%)$ were also reported by the travel blog authors. Again, these states of mind are linked to the benefits of touch. Similarly, they are connected to the ambience that the spa provided. The use of essential oils, which is commonplace in Asian spas, is thought of as a contributory factor to these feelings. Based on this assumption, these results can be underpinned by medical research on aromatherapy. The use of essential oils in massages (i.e. aromatherapy massage) is recognized in the modern-day medical field as one of the complementary/alternative medical treatment options. In a study by Cooke and Ernst (2000), it was suggested that aromatherapy massage has a mild, transient anxiolytic effect (meaning it reduces anxiety). In addition to the benefits of aromas, the physical feel (fixtures, furniture, and lighting) and perhaps, music also contribute to feelings of peacefulness and calmness.

\section{The Socio-Environmental Dimension}

The elements of social and environmental dimensions were combined because of some linkages observed in a few of the blogs. In the social dimension, positive connections with the bloggers' companions (spouse/partner, family, friends, and/or fellow travelers) were reportedly enhanced ( $n=22$, $17.6 \%$ ). It was observed that the treatments received by the individuals who reported this outcome were being given in a less personal space that is, not in private massage rooms. More specifically, the treatments involved foot spa, facials and sauna. These spa services are usually given in shared spaces; hence spa-goers have more opportunities to interact. 
About 21 per cent and 25 per cent of the filtered sample appreciated nature $(\mathrm{n}=26)$ and the products derived from it $(\mathrm{n}=31)$ during the treatments respectively. A few of the blogs had a sense of duality in their stories, where the appreciation of nature and the products derived from it was the topic of the conversation with a companion(s) during the treatment sessions. Geena recalls, "we (referring to her sister) were sipping fresh coconut juice earlier and next thing we knew they were applying coconut oil on us. We decided that it was going to be a coconut day!!!! We bought coconut products on that day!! Nikki spent most of her money on accessories made of coconuts... No jokes... they're expensive!!!!”

\section{Conclusions and Implications}

The findings in the blog study can be summarised in terms of the aims that were identified earlier. Firstly, this study sought to identify the volume of existing travel blogs containing information on spa experiences in South East Asia. A systematized method of searching blogs involved using and matching key words and the name of the country/sub-region. After choosing more specific keyword combinations, 97,000 blogs were streamlined to one per cent of the blogs searched $(n=972)$ and were coded. Secondly, this study sought to identify the benefits which the respondents thought they received from their spa experience.

The significance of spa activities as a source of positive experiences and as contributors to well-being were recognized in this paper. Also, the multidimensionality of wellness has been reinforced in this study. The positive thoughts and feelings of tourist spa-goers which are conceived as benefits in this study vary in terms of the dimensions of wellness. Tourist spa-goers reported positive experiences in the physical, psychological and socioenvironmental dimensions. One's physical domain is affected by touch during spa treatments. The psychological dimension (emotional, intellectual and sometimes spiritual domains) involves the feelings and thoughts during and after the spa experiences. A person's social dimension is affected through perceived improvement in relationships as a result of the spa experience, while one's environmental dimension is affected by the perception of proximity or connection to nature during the experience, or the actual use of nature-derived spa treatment products. 
The implications and applications of this study are three-fold: conceptual, practical and commercial. The conceptual contribution of this study lies in the exploration of tourist spa experiences in travel blogs. The investigation of such experiences using blog analysis offers novelty in terms of methodology. The practical applications and commercial considerations are interrelated in this study; the results in this study indicate that the participants reported a considerable degree of positive response about their spa experience while travelling. Tourist wellbeing is seen as the core concept. The focus on South East Asia and on the ways tourists experience spas offers additional marketing perspectives for businesses. The advantage of focused regional studies of tourism lies in specifying how businesses differ and can be managed in local contexts. It is possible to tailor promotional strategies that target specific market segments. Aptly communicating the benefits of spa experiences to target markets is important; the use of language in promotional materials should also correspond to the target market's level of spa use, travel experience and knowledge. This consideration for commercial and marketing processes does not only apply to tourists but also local users of spa businesses.

\section{References}

Bowen, D., \& Clarke, J. (2009). Contemporary Tourist Behaviour: Yourself and Others as Tourists. Wallingford: CABI.

Carson, D. (2008). The 'blogosphere' as a market research tool for tourism destinations: A case study of Australia's Norther Territory. Journal of Vacation Marketing, 14(2), 111-119.

Caru, A., \& Cova, B. (2008). Small versus big stories in framing consumption experiences. Qualitative Market Research, 11(2), 166-176.

Chapman, J. (2006). Ultimate Spa: Asia's Best Spas and Spa Treatments. Singapore: Periplus Editions.

Cohen, E. (1979). A phenomenology of tourist experiences. Sociology, 13, 179201.

Cohen, E. (1996). A phenomenology of tourist experiences. In Y. Apostolopoulos, S. Leivadi \& A. Yiannakis (Eds.), The Sociology of Tourism (pp. 90-114). Oxford: Rutledge.

Connell, J. (2006). Medical tourism: Sea, sun, sand and... surgery. Tourism Management, 27, 1093-1100. 
Crotts, J. C., Mason, P. R., \& Davis, B. (2009). Measuring guest satisfaction and competitive position in the hospitality and tourism industry: An application of stance-shift analysis to travel blog narratives. Journal of Travel Research, 48(2), 139-151.

Decrop, A. (2004). Trustworthiness in qualitative tourism research. In J. Phillimore \& L. Goodson (Eds.), Qualitative Research in Tourism: Ontologies, Epistemologies and Methodologies (pp. 157-169). London: Routledge.

Didascalou, E. A., Nastos, P. T., \& Matzarakis, A. (2007). Spa destination development using a decision support system - The role of climate and bioclimate information. Developments in Tourism Climatology, 2007, 158-165.

Diekmann, A., \& Hannam, K. (2012). Touristic mobilities in India's slum spaces. Annals of Tourism Research, 39(3), 1315-1336. doi: 10.1016/j.annals.2012.02.005

Douglas, A., \& Mills, J. (2006). Logging brand personality online: Website content analysis of Middle Eastern and North African destinations. In M. Hitz, M. Sigala \& J. Murphy (Eds.), Information and Communications Technologies in Tourism. New York: Springer Wien.

Douglas, N. (2001). Travelling for health: Spa and health resorts. In N. Douglas, N. Douglas \& R. Derrett (Eds.), Special Interest Tourism (pp. 260282). Milton, Queensland: John Wiley and Sons Australia.

Gagne, D., \& Toye, R. C. (1994). The effects of therapeutic touch and relaxation therapy in reducing anxiety. Archives of Psychiatric Nursing, 8(3), 184-189.

Global Spa Summit. (2008). The Global Spa Economy 2007: Stanford Research Institute (SRI) International.

Hall, M. (2005). Spa and health tourism. In S. Hudson (Ed.), Sport and Adventure Tourism (pp. 273-392). New York: Haworth Hospitality Press.

Henry, R. D. (2005). Spa State of Mind. In R. D. Henry \& J. D. Taylor (Eds.), Spa: The Sensuous Experience (pp. 6-7). Mulgrave, Victoria: Images Publishing Group.

Iovine, J. V. (2005). The History of Spa In R. D. Henry \& J. D. Taylor (Eds.), Spa: The Sensuous Experience (pp. 8-11). Mulgrave, Victoria: Images Publishing Group. 
Kaspar, C. (1990). A new lease on life for spa and health tourism. Annals of Tourism Research, 17(2), 298-299.

Kerala Ayurveda Tourism. (2009). Kerala Ayurveda Retrieved 15 January 2010, from http://www.keralaayurvedatourism.com/

Kozinets, R. V. (1997). 'I want to believe': A netnography of the X-philes' subculture of consumption. In M. Brucks \& D. J. MacInnis (Eds.), Advances in Consumer Research (Vol. 24, pp. 470-475). Provo, UT: Association for Consumer Research.

Kozinets, R. V. (1998). On Netnography: Initial reflections on consumer research investiagations of cyberculture. In J. Alba \& W. Hutchinson (Eds.), Advances in Consumer Research (Vol. 25, pp. 366-371). Provo, UT: Association for Consumer Research.

Kozinets, R. V. (1999). E-tribalized marketing? The strategic implications of virtual communities of consumption. European Management Journal 17(3), 252-264.

Kozinets, R. V. (2002). The field behind the screen: Using netnography for marketing research in online communities. American Marketing Association, 39(1), 61-72.

Kozinets, R. V. (2010). Netnography: Doing Ethnographic Research Online. London: SAGE Publications.

Laing, J., \& Weiler, B. (2008). Mind, Body and Spirit: Health and Wellness Tourism in Asia. In J. Cochrane (Ed.), Asian Tourism: Growth and Change (pp. 379-389). Oxford: Elsevier Ltd.

Lopez-Bonilla, J. M., \& Lopez-Bonilla, L. M. (2010). Tourism planning in subregional destinations: Heterogeneity of the tourist experience on the Andalusian Coastal Municipalities

European

Planning Studies, 18

(11), 1821-1836.

Messerli, H., \& Oyama, Y. (2004). Health and Wellness Tourism, Travel and Tourist Analyst. London: Mintel International Group.

Mind Body \& Soul. (2009). Cupping Retrieved 23 June, 2010, from http://www.mindbodysoul.tv/health/cupping.html

Nardi, B. A., Schiano, D. J., Gumbrecht, M., \& Swartz, L. (2004). Why we blog. Communcations of the ACM, 47(12), 41-46.

National Institutes of Health. (2010). Massage Therapy Retrieved 11 March 2010, from http://www.nlm.nih.gov/medlineplus/tutorials/massagetherapy/am019 103.pdf 
North Haven Spa. (2007). Spa Services Retrieved 23 June 2010, from http://northhaven.multiply.com/

Pan, B., MacLaurin, T., \& Crotts, J. C. (2007). Travel blogs and the implications for destination marketing. Journal of Travel Research, 46(Aug 2007), 35-45.

Panchal, J. H., \& Pearce, P. L. (2011). Health motives and the travel career pattern (TCP) model. Asian Journal of Tourism and Hospitality Research, 5(1), 32-44.

Pearce, P. L., \& Foster, F. (2007). 'University of Travel': Backpacker learning. Tourism Management, 28, 1285-1298.

Pearce, P. L., \& Panchal, J. H. (2010). The integration of health as a travel motive factor in the Travel Career Pattern (TCP) model. Paper presented at the 16th Annual Conference of the Asia Pacific Tourism Association, Macau, SAR.

Rice, R. E., \& Rogers, E. M. (1984). New methods and data for the study of new media. In R. E. Rice (Ed.), The new media: Communication, research and technology. Beverly Hills: SAGE.

Sanctuario Spa. (2009). Sanctuario Spa: Filipino Traditional Healing Retrieved 23 June 2010, from http://sanctuariospa.com/services-andpackages/id/filipino-traditional-healing

Sharda, N., \& Ponnada, M. (2008). Tourism blog visualizer for better tour planning. Journal of Vacation Marketing, 14(2), 157-167.

Smith, M., \& Duffy, R. (Eds.). (2003). The Ethics of Tourism Development. London: Routledge.

Smith, M., \& Kelly, C. (2006a). Wellness Tourism. [Editorial]. Tourism Recreation Research, 31(1), 1-4.

Smith, M., \& Kelly, C. (2006b). Holistic Tourism: Journeys of the self? Tourism Recreation Research, 31(1), 15-24.

Smith, M., \& Puczko, L. (2009). Health and Wellness Tourism. Oxford: Butterworth-Heinemann.

Spa Wellness Council. (2008). About APSWC Retrieved 30 July 2008, from http://www.spawellnesscouncil.com/

Spitzer, D. (2009). Ayurvedic Tourism in Kerala: Local identities and global markets. In T. Winter, P. Teo \& T. C. Chang (Eds.), Asia On Tour: Exploring the Rise of Asian Tourism (pp. 138-150). London: Routledge. 
The Spa Village. (2008). Traditional Spa Experience Retrieved 23 June 2010, from http://www.spavillage.com/pangkorlaut/spapackages/traditional.htm

United Nations Department of Economic \& Social Affairs. (2011). Composition of macro geographical (continental) regions, geographical sub-regions, and selected economic and other groupings Retrieved 23 June 2011, from http://unstats.un.org/unsd/methods/m49/m49regin.htm

Received June 1, 2014

Revised December 31, 2014

Accepted December 31, 2014 